\title{
Developing A Conceptual Model that Illuminates the Dynamics of Performativity within Technological Innovation
}

\author{
Joan Edwards \\ Jim Lawlor
}

\author{
Waterford Institute of Technology, Ireland
}

\begin{abstract}
:
Technological innovation is a process that involves the intertwining of social, cognitive, and material elements. The relationship among these features is non-linear, complex, and possesses the ability to transform as well as inform the configuration of markets, tools, users, and social environments. The concept of performativity can be used to explain this phenomenon. This paper identifies the performative elements present in the context of technological innovation and maps the social factors and the use of cognitive features in the innovation process. This identification explicitly addresses the entanglement of the material and social influences in the process, defines the agency of technological change, and focuses on the impact the nature of a technology has on the configuration of a market. A conceptual model of performativity in the innovation process is proposed.
\end{abstract}

Keywords: Technological Innovation; Performativity; Entanglement; Conceptual Model 


\section{Introduction}

There have been several endeavours at modelling the dynamics inherent in the process of technological innovation (for example Forrest, 1991; Dodgson and Rothwell, 1995; Tidd, Bessant and Pavitt, 2005; Chen and Vanhaverbeke, 2019); however, the complexities of the interactions between the various interwoven technological and societal issues have led to frequent revisions. To examine this process, external and multidisciplinary knowledge is needed to define what is entailed within the technological change and how the phenomenon of performativity (within the context of innovation) affects societies (Cecez-Kecmanovic and Kautz, 2013). The question is one that goes to the root of what is effecting and affecting change, and how elements of technology such as its material artefacts intermingle with social entities (Köhler, Raven and Walrave, 2020).

Dosi (1999) defines innovation as the technological development of an invention combined with the market introduction of that invention to end-users. Yet, innovation is not merely invention but instead incorporates the context in which an invention is applied. For a technological artefact to be truly innovative, it must address a need and interact with the market. Linear models of technological innovation offer simplified and defined processes for bringing ideations or inventions to market. Implicit in these models is the belief that success in innovation is the degree to which marketization is achieved, an idea which remains popular (Peng and Sanderson, 2014).

The more complex a new technology is, the more challenging it is for society in terms of changing roles, and the less linear this route through idea-invention-marketization becomes (Rip, 2018). In these cases, the route to marketization requires a diverse and overlapping set of skills and knowledge to manage successfully. While invention is seen as involving factors such as creativity, fundamental scientific knowledge and research and development ( $\mathrm{Li}$ et al., 2013), marketization is perceived in terms of segmentation, diffusion and distribution channels. These and associated factors are substantial challenges in better understanding the overall process of technological innovation and are the focus of ongoing commercial work as well as the focus of innovation topics which include creative destruction, crossing the chasm, and disruptive technology.

\section{Problem Outline}

The development of the material products of the technological innovation process, artefacts, is not a static event. Technological artefacts have a life history, which involves a specific sequence of interactions between humans and physical materials (Hollenback and Schiffer, 1999; Aunger, 2010). A model of this interaction is depicted in Figure 1.

The stages of this model signpost interactive events between humans and artefacts. In the preparation phase, humans interact with raw material or the idea of the artefact. Preparation is defined as the means by which humans acquire the knowledge, motivation, and ability necessary to produce an artefact. This entails the creation and initial development of ideas and concepts. In the production phase a new artefact

International Journal of Management and Applied Research, 2021, Vol. 8, No. 3 
comes into being; in this phase, development may be repeated, and the idea may go through several iterations. It is after this stage that interaction normally results in humans achieving benefits through 'artefact-enabled behaviour' (Aunger, 2010). Further developments may be carried out as a result of human interaction with the artefact, resulting in future iterations. These iterations maintain or advance an artefact's functionality. Abandonment/disposal is the process through which a human loses its interest to the artefact. This concept of an artefact's life history, mimics the theory that chronicles the development, acceptance, and obsolescence of technologies that enter the market (Rogers, 1995). This suggests that successful market introduction efforts for technological artefacts are influenced by social, cognitive, and environmental factors that inform the development of both the user and artefact within the process.

Figure 1 Technology artefact's life history

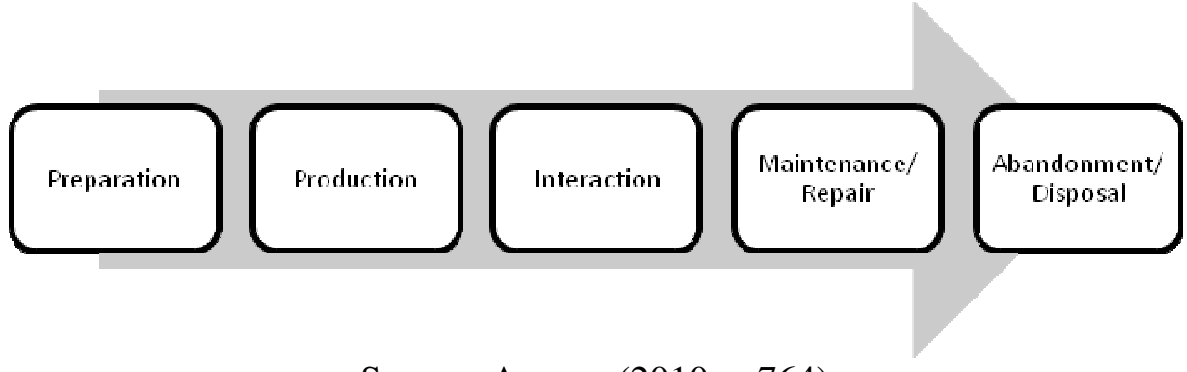

Source: Aunger (2010, p.764)

Technology is a phenomenon that is 'revealed' (Heidegger, 1977, p.8) through an interactive and iterative (Bijker, Hughes, Pinch, and Douglas, 2012; Aunger, 2010) process between developers, end-users, and material artefacts. Within this process, knowledge is created and the user guides as well as is guided by the artefact. Given that technology involves such a range of factors and dynamic processes, it is useful to consider different perspectives on how artefacts are developed.

The way in which a technological artefact is used cannot be understood without 'perceiving how that technology is embedded in its social context' (Bijker et al., 2012, p. 271). Many of the models of technological innovation share characteristics that are applicable to this concern, including a focus on parallel activities, the overlapping nature of various stages of innovation, as well as focus on iteration and feedback. These characteristics describe the interactions between innovators and markets-which comprise various human and non-human actors-that result in the construction of networks, and which focus on the of interlacing of entities and their actions (Garud, et al., 2013). The 'entanglement' (Orlikowski, 2005, p.185) of social and technological factors in the technological innovation process, refers to the 'intertwining and reciprocal inter-definition of human agency' (Pickering, 1995, p.26) related to the development of technologies.

Technological innovation as a system is influenced by feedback and repetition; sequential introductions of a technological artefact incrementally lead to a finalised

International Journal of Management and Applied Research, 2021, Vol. 8, No. 3 
version of a product as well as a series of new ideas and concepts (Etzkowitz, 2002; Berkhout et al., 2000). This highlights two points:

- There is iteration inherent in the innovation process, in which an invention is improved and subsequent ideas and innovator actions are refined (Garcia and Calantone, 2002).

- Actions are repeated as a series of activities performed within an environment and are executed according to a sequence; this is indicative of routine (Kline and Rosenberg, 1986; Gardner, 1983).

The iterative elements of innovation models stipulate that all innovation activities are always present and are constantly moving in order to establish the relationship between the technology and the end-user. The elements are achieved through communicative actions that highlight both social and cognitive components within the process. The innovation may be perceived as an interactive, recursive, time-dependent process of socio-technological impregnation, in which promises about technologies and social relations are played off against one another in the search for durable solutions (Godin, 2010).

Within the technological innovation process, the dominance of particular elements in the relationships between technology, innovators, end-users and other contributors, change over time as the technology and market develop. Ultimately, the inherent intricacies involved in bringing a technology to market result from the social factors that arise from collaboration and interaction. Ergo, it is understood that technologies and markets emerge from a complex series of activities within a constantly changing environment (Araujo, Finch and Kjellberg, 2010).

This series of complex innovation activities result from social and cognitive factors which inform both the technology and the market (Çalışkan and Callon, 2010). The innovation and the market interact to transform, and eventually, constitute the environment of which they become a part.

The concept of performativity has been used in various disciplines to describe the phenomenon of when social elements and actions, effect change and shape reality (Marti and Gond, 2018). The key objective of this research is to define and identify performativity within the context of technological innovation and integrate performative elements into a conceptual model of the innovation process.

In that context, the assumptions about performativity within the innovation process are the following:

- Performativity constitutes a key element of the process of technological innovation.

- The characteristics of technological innovation, in terms of performativity, can be defined.

- Characteristics of performativity can be applied to further technological innovation cases and their associated markets.

International Journal of Management and Applied Research, 2021, Vol. 8, No. 3 


\section{Theoretical Background}

The concept of performativity claims that social elements (and acquired knowledge), when carried out into the world, 'reformat and reorganise the phenomena they purport to describe' (Healy, 2015 p. 4) - often bringing the world into line with theory; this is in stark contrast to the conventional belief that theories are explanations that merely aim to describe observable occurrences. Within the concept of performativity, actors become performative when they do more than describe a given reality, but also change the social reality they are describing. In this sense, performativity is not merely performance, but connects an entity, its performance, and how it is perceived within social contexts. The interactions and actors frame social arenas according to the premises of theories and turn these theories into actions (Durisin and Todorova, 2012). As the dimensions and complexity of actors and interactions are dynamic, by constructing identity through routine, theoretical constructs are not simply guiding but contribute to actively shaping actual processes (Mackenzie, 2007). Ultimately, a process is performative if it affects the transition from one conventionally defined state or paradigm to another (Garud and Gehman, 2019).

\subsection{Origin of the Term Performativity}

An outline of the concept of performativity was developed by J.L. Austin in How to do things with words (1962). Austin challenged the idea that in speech an utterance can be merely true or false, irrespective of the context within which it arises. For example, in considering the statement "I resign from this position", Austin suggests that not only is the statement true (assuming it is), but that by making the statement, the individual making it changes the relationship between him/herself and the relevant organization in a fundamental way. In uttering sentences of this kind, the speaker thereby does something more than merely state something - the speaker performs a reality. Such utterances are regarded as performatives in order to contrast performing an action which simply describes something.

In all cases of meaningful utterance, to say something is to perform the act of making certain noises, to perform the act of forming certain words and to perform the act of combining words in such a way that they have meaning.

Every utterance is malleable, with "true" and "false" merely reflecting the extent to which an utterance is a right or proper thing to say as opposed to a wrong thing, in circumstances. In applying Austin's concept of speech acts and performativity, the following characteristics of performatives are identified:

- Performatives do not merely describe or report

- They are not true or false

- Uttering a performative is part of doing an action

According to Austin (1962), context impacts the meaning of an utterance - there is no objective or universal truth, only intersubjective truth. For instance, the utterance 'I resign' has significant impact, and changes the relationship as well as organizational

International Journal of Management and Applied Research, 2021, Vol. 8, No. 3 
structure when said by an employee to employer. This utterance has far less impact and fewer consequences outside of this context.

The context of an utterance can never be fully determined because words and concepts rely, for their meaning, on other words and concepts, with no stable ground (Derrida, 1988). The dynamic environment in which performativity is applied emphasises the significance of routine (Gardner, 1983; D'Adderio, 2008) in providing some degree of shared understanding. Because the environment has multiple entities that are constantly changing, and relationships that shift and alter, routine is important in establishing a steady-state (effected permanence) for the relationships. For example, the performative utterance 'I resign' has a clearly understood meaning in the context of the relationship between an employee and an employer due to its repeated use over time and the associated action that it achieves.

\subsection{Performativity Literature}

The concept of performativity has application in a variety of fields such as linguistics, anthropology, economics, gender studies, science and technology studies (STS) and philosophy.

In understanding performativity, as defined in the field of gender studies, identity is not substantive, unified, or internally coherent - sex and gender distinctions are multiple, fluid, and non-substantive (Butler, 1997; Diamond and Butterworth, 2008). According to this theory gender is not a stable identity or locus of agency from which various acts follow; rather, gender is an identity tenuously constituted in time, instituted in an environment, through a stylized repetition of acts. These repetitive actions create a routine. New forms of gender arise from mutations in the repetition of these acts. The actions of a subject inform, but are also informed by, the results of the subject repeating or being repeated with tools that determine the subject's identity (Barad, 2003). It may be supposed that gender identity is realised only through repeated actions in which an intersubjective perspective may be applied. What is perceived as a gender is purported by societal conventions brought about by routine. Performativity endorses the idea that the power of a subject is not the function of an originating will but is always derivative.

This idea of performativity also reverberates in such fields as economics. Application of the concept is evident in the relationship between the Chicago Board Options Exchange and the Black-Scholes-Merton (BSM) options pricing model. The BSM Option pricing theory highlights performative elements, because of the model preexisting price patterns, and because markets—subsequent to its publication-changed in ways that made its assumptions more accurate; it reformatted the social context and allowed for the theory to be used in arbitrage. Consequently, it can be understood that Economics more than describes an external world, but instead shapes its own identity (Maki, 2013 p.3).

The discussion surrounding performativity has extended to the fields of information systems (IS) and science and technology studies (STS). Within these areas, performativity is explored as a means of explaining the entanglement (Orlikowski,

International Journal of Management and Applied Research, 2021, Vol. 8, No. 3 
2005; Scott and Orlikowski, 2014) that exists between the social and material aspects of an interaction, and the technological artefacts that arise.

The literature is diverse but there are common themes that resonate across the various disciplines and assert performativity is a multi-way exchange that entails social, communicative, and cognitive factors that inform development.

\section{Developing a Conceptual Model}

Though the literature surrounding the concept of performativity is varied, there are common characteristics that are embraced amongst the various disciplines that identify both communicative and cognitive elements. The communicative characteristics are identified as feedback, iteration, and routine.

\subsection{Communicative Elements of Performativity within the Technological Innovation Process}

The flow of information is an integral part of the development within the innovation process and is catalysed by feedback, both from the innovators as well as the end users in the market. Feedback is the communication fostered within the process. It is the transfer of information regarding reactions to actions, the development of material artefacts, or the performance of tasks within the innovation process. It influences the modification of a process or artefact to help propel the innovation process and initiates further instances of feedback. Feedback promotes iteration which is the repetition of a process or procedure or activity. It is done to obtain successively closer approximations to the final artefact or solution to an issue conceived during the ideation phase.

Figure 2: Communicative elements of the technological innovation process

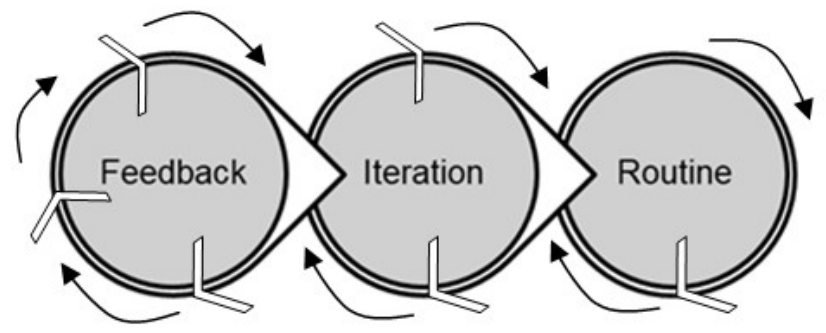

Repeated feedback is performed in a particular manner and performativity literature addresses the phenomenon of repeated action done in a certain way as routine (Gardner, 1983); it is the creation of knowledge or performative agency as a result of routinely acted procedures. Routine is the continued iteration of feedback performed in a particular manner and is the sequence of actions performed in a particular method.

As depicted in Figure 2, there is routine in the way feedback and iterations arise (e.g. how information may be received, how feedback is fostered). Often, once the product

International Journal of Management and Applied Research, 2021, Vol. 8, No. 3 
reaches a terminus in development, a new idea emerges that may displace the artefact that exists in the market. This is evident in such concepts as the product life cycle.

Modelling the communicative elements represented in the innovation process does not focus on or illustrate the recursive features that exhibit performative qualities by informing actions. If it its contended that the initial idea is merely a suggestion and that several factors influence the overall development and output of the final artefact, then this needs to be explicitly addressed within a conceptual model. Additionally, a model of performative innovation should highlight the various stakeholders involved, the influence of such stakeholders, and the interaction between the material and the social within the innovation development process. The question can be asked "what factors are driving the development of the innovation?'

\subsection{Cognitive Elements of Performativity within the Technological Innovation Process}

Feedback, iteration, and routine describe the innovation process at the macro level but do not provide evidence of how or why communicative actions occur. A model derived using only these three characteristics disregards the perceptive influence of those who interact with a technological artefact and neglects why the environment may also be transformed in the innovation process.

The concept of affordances may be used to address this issue. Affordances are a sociomaterial construction (van Dijk and Rietveld, 2017) that represent the complex interactions between multiple social actors and material artefacts within a given environment. Affordances are the properties of an artefact that define its possible uses or potential; it is a resource that the environment offers an actor/agent. Norman (1999) attributes the use of affordances for enacting purposeful design. The innovator designs based on stimuli from the environment, by perceiving the needs of the environment, interpreting the perceptions and developing an artefact towards a goal. Furthermore, end users have goals that they evaluate to fit the environment and the goals are motivated by expectations within the process.

Motivations are the reasons for acting or behaving in a particular way to garner feedback and promote movement within the innovation process and expectations are strong beliefs about the ways in which an artefact will affect a user, market or another artefact. Motivations and expectations are present for all agents within the innovation process but refine as the process goes through different iterations.

The process is complex because there are several stages of progression as different iterations provide different information and possible different artefacts. Additionally, in the performative model, the assertion is that not only are affordances between users and the material artefact but also between the user and environment as well as the environment and the artefact.

\subsection{Conceptual Model of Performativity within the Technological Innovation Process}

A conceptual model of performativity within the technological innovation process was developed and is illustrated in Figure 3. The model shows the bidirectional flow

International Journal of Management and Applied Research, 2021, Vol. 8, No. 3 
between the cognitive and communicative elements within innovation environment, as opposed to unidirectional information flows represented in linear models of innovation. The broken lines also indicate permeability that accommodates the freeflowing movement of information and encourages transformation.

The conceptual model depicts feedback continually happens between the technological artefact and the user. Repeated feedback and communication are part of an iterative process and create knowledge, both for the innovator and for the end-user. Routine is the mode by which this knowledge gains meaning. By repeating a practice (iteration) in a sequence (routine) an understanding and identity is created. Continued feedback promotes iteration and iterations that repeatedly perform the same types of tasks with an end goal, signify routine.

When a user interacts with an artefact, the user realizes actions that they are able to perform because of the artefact. The affordances promote agency and the user is able to distinguish possibilities for action in the environment; an affordance is some possibility for action that is mutually specified by the user and the environment.

There are multiple permutations for the development of elements within a performative relationship, and the path which particular elements follow is contingent on the environment and factors that influence their development. In any particular case, the actors involved, and the conditions must be appropriate to the invocation of the procedure. It is by the actions carried out using routine procedure and having a certain understood outcome by appropriate actors in appropriate conditions, that an identity is formed.

\subsection{Challenges of modelling the performative innovation process}

In modelling innovation, there are two basic approaches to discovering "truth": the deductive approach and the inductive approach. The deductive approach starts with examples or axioms about the world in which the system works; understanding the phenomenon can be deduced from the nature of the axioms. Conversely, the inductive method starts with the conclusion - the truths describing the phenomenon are the goal of the investigation.

Linear models of innovation align with a deductive approach. Yet, the complexity of a performative model, aligns more an inductive approach, and at times may even require transductive reasoning - in which connections between seemingly unrelated elements may be linked. With the complexity of the process, it is understood that there are no set examples or axioms to follow. The process is messy and not very predictable; the conditionals (environment and social) are always changing.

Expectations and motivations inherently introduce burdens to this system. The developed performative innovation model cannot be constrained by expectations and motivations, but instead merely guided, since these elements are likely to change and adapt throughout the iterative process of innovation.

International Journal of Management and Applied Research, 2021, Vol. 8, No. 3 
Figure 3: Conceptual model of performativity within technological innovation

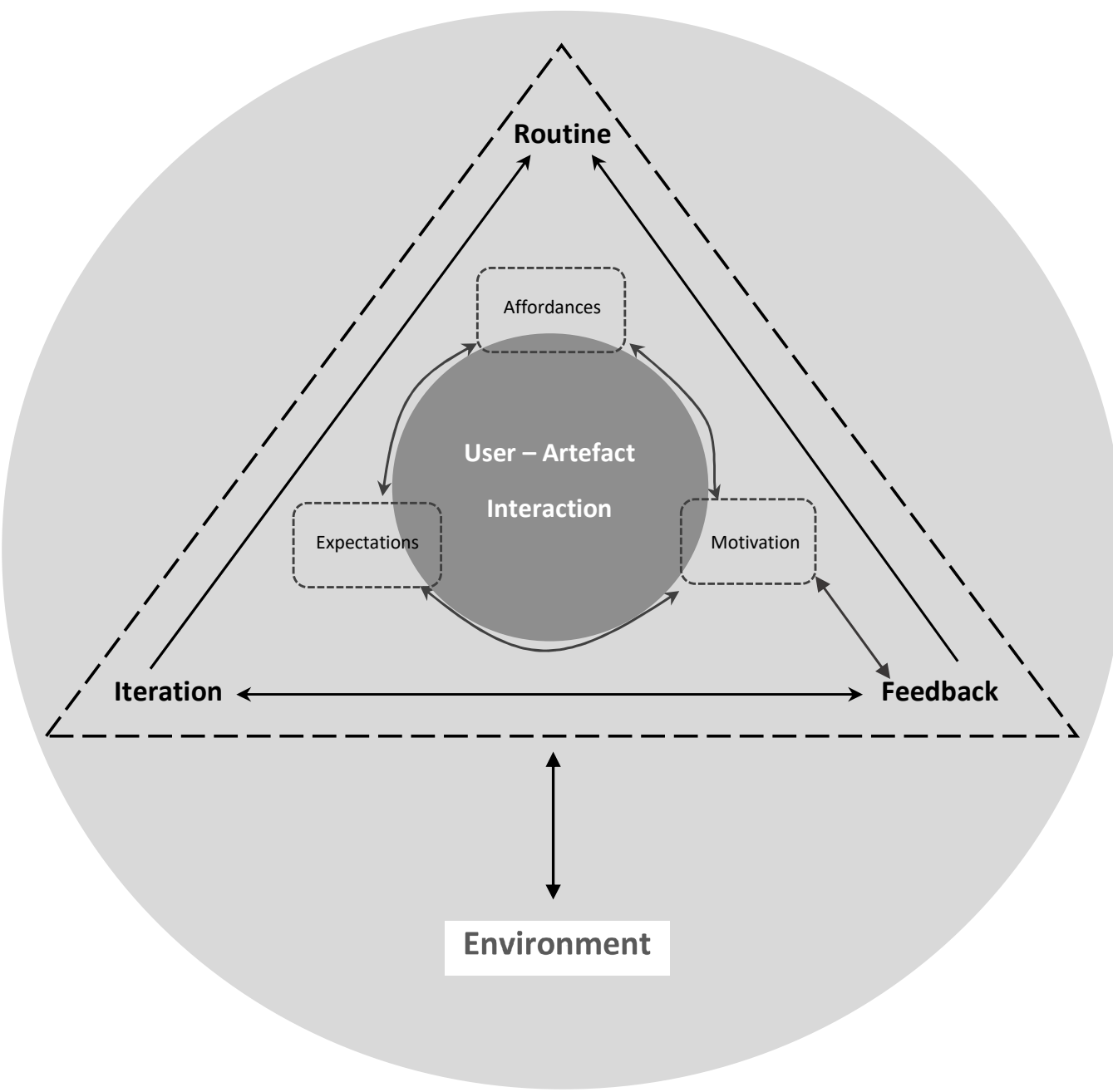

\section{Conclusion}

In this paper, the term performativity is defined within the context of technological innovation, a conceptual model is proposed to illustrate dynamics of performativity.

Performativity denotes the ability to create a reality by enacting practice and prescribing function to artefacts, while considering the impact artefacts have on the development of the environment. In this research, it is revealed performativity is defined as the development of an identity through the iterative process of classifying the actions and the influences that the use of artefacts have on an environment. The conceptual model developed, attempts to illustrate that the identities of the users, artefacts, and environment, within a performative model are prone to transformation. There is not one exact configuration for the construction of an entities' identity, instead the users and artefacts are malleable and pliable - having the ability to change based on the environment they become a part of. This identity is constructed through

International Journal of Management and Applied Research, 2021, Vol. 8, No. 3 
repeated acts, supporting the idea that not only feedback, but iteration is crucial within the performative process.

Feedback, iteration, and routine are identified as the communicative elements of the process. Affordances, expectations, and motivations are recognised as the cognitive elements in the innovation process. These factors interact in a dynamic and transmutative environment, to produce a technological artefact that goes to market.

The construction of a conceptual model and the research findings surrounding performative innovation are useful, but this study also has many limitations. Adding a comparative analysis will provide further evaluation of performative implications and can illustrate a clearer picture of the innovation trajectory. This methodology will be incorporated in future works to better elucidate features of how innovation patters morph over time.

This research contributes to the understanding of how technological capabilities differ in development and addresses the social and cognitive factors that influence the process. A better understanding of the factors that influence the technological innovation process can help improve the success rate associated with technological diffusion, address issues in the replication dilemma, stimulate greater innovative activity and minimise the occurrence of disappointing innovations.

\section{References}

1. Araujo, L., Finch, J. and Kjellberg, H. (eds.) (2010), Reconnecting marketing to markets. Oxford: Oxford University Press. https://doi.org/10.1093/acprof:oso/9780199578061.001.0001

2. Aunger, R., (2010), "Types of technology", Technological Forecasting and Social Change, Vol. 77, No. 5, pp.762-782.

3. Austin, J. L. (1962), How To Do Things with Words. Cambridge: Harvard University Press

4. Barad, K. (2003), "Posthumanist performativity: Toward an understanding of how matter comes to matter", Signs: Journal of women in culture and society, Vol. 28, No. 3, pp. 801-831. https://doi.org/10.1086/345321

5. Berkhout, A.J., Hartmann, D., Van Der Duin, P. and Ortt, R. (2006), "Innovating the innovation process", International journal of technology management, Vol. 34, No. 3-4, pp.390-404. https://doi.org/10.1504/IJTM.2006.009466

6. Bijker, W.E., Hughes, T.P., Pinch, T. and Douglas, D.G., (2012), The social construction of technological systems: New directions in the sociology and history of technology. Cambridge: MIT press.

7. Butler, J. (1997), Excitable Speech: A Politics of the Performative. New York: Routledge.

International Journal of Management and Applied Research, 2021, Vol. 8, No. 3 
8. Çalışkan, K. and Callon, M. (2010), "Economization, part 2: a research programme for the study of markets", Economy and Society, Vol. 39, No. 1, pp.1-32. https://doi.org/10.1080/03085140903424519

9. Chen, Y. and Vanhaverbeke, W. (2019), "Concept and connotation of open innovation", in: Chen, J.; Brem, A., Viardot, E. and Wong P. K. (Eds), The Routledge Companion to Innovation Management, Abingdon: Routledge. https://doi.org/10.4324/9781315276670-3

10. D'Adderio, L. (2008), "The performativity of routines: Theorising the influence of artefacts and distributed agencies on routines dynamics", Research Policy, Vol. 37, No. 5, pp. 769-789.

11. Derrida, J. (1988), Limited Inc. Evanston: Northwestern University Press.

12. Diamond, L.M. and Butterworth, M., (2008), "Questioning gender and sexual identity: Dynamic links over time", Sex roles, Vol. 59, No. 5-6, pp.365-376. https://doi.org/10.1007/s11199-008-9425-3

13. Dodgson, M. and Rothwell, R. (1995), The handbook of industrial innovation. UK: Edward Elgar Publishing.

14. Dosi, G., (1999), "Some notes on national systems of innovation and production, and their implications for economic analysis", In D. Archibugi, J. Howells, \& J. Michie (Eds.), Innovation Policy in a Global Economy. Cambridge: Cambridge University Press. pp. 35-48 doi:10.1017/CBO9780511599088.005

15. Durisin, B. and Todorova, G. (2012), "A study of the performativity of the "ambidextrous organizations" theory: Neither lost in nor lost before translation",. Journal of Product Innovation Management, Vol. 29, S1, pp.53-75. https://doi.org/10.1111/j.1540-5885.2012.00981.x

16. Etzkowitz, H. (2002), "Incubation of incubators: innovation as a triple helix of university-industry-government networks", Science and Public Policy, Vol. 29, No. 2, pp.115-128. https://doi.org/10.3152/147154302781781056

17. Forrest, J.F., (1991), "Practitioners' forum: Models of the process technological innovation", Technology Analysis \& Strategic Management, Vol. 3, No. 4, pp.439453. https://doi.org/10.1080/09537329108524070

18. Garcia, R. and Calantone, R. (2002), “A critical look at technological innovation typology and innovativeness terminology: a literature review", Journal of Product Innovation Management: An international publication of the product development \& management association, Vol. 19, No. 2, pp.110-132. https://doi.org/10.1016/S0737-6782(01)00132-1

International Journal of Management and Applied Research, 2021, Vol. 8, No. 3 
19. Gardner, D.S. (1983), "Performativity in ritual: the Mianmin case", Man, Vol. 18, No. 2, pp. pp.346-360.

20. Garud, R.; Tuertscher, P. and Van de Ven, A. H. (2013), "Perspectives on Innovation Processes", Academy of Management Annals, Vol. 7, No. 1, pp. 775819, https://doi.org/10.5465/19416520.2013.791066

21. Garud, R. and Gehman, J. (2019), "Performativity: Not a destination but an ongoing journey", Academy of Management Review, Vol. 44, No. 3, pp. 679-684. https://doi.org/10.5465/amr.2018.0315

22. Godin, B. (2012), "Innovation Studies: The Invention of a Specialty", Minerva, Vol. 50, No. 4, pp. 397-421. https://doi.org/10.1007/s11024-012-9212-8

23. Healy, K., (2015), "The performativity of networks", European Journal of Sociology, Vol. 56, No. 2, pp.175-205.

24. Heidegger, M. (1977), The question concerning technology, New York: Harper \& Row.

25. Hollenback, K.L. and Schiffer, M.B. (2010), "Technology and material life", in: Hicks, D. and Beaudry, M, C. (Eds), The Oxford handbook of material culture studies, pp.313-332. https://doi.org/10.1093/oxfordhb/9780199218714.013.0013

26. Kautz, K. and Cecez-Kecmanovic, D. (2013), "Sociomateriality and information systems success and failure", In: Dwivedi Y.K., Henriksen H.Z., Wastell D., De' R. (Eds) Grand Successes and Failures in IT. Public and Private Sectors. TDIT 2013. IFIP Advances in Information and Communication Technology, Vol. 402. Berlin: Springer. https://doi.org/10.1007/978-3-642-38862-0_1

27. Köhler, J., Raven, R. and Walrave, B. (2020), "Advancing the analysis of technological innovation systems dynamics: Introduction to the special issue", Technological Forecasting and Social Change, Vol. 158, 120040. https://doi.org/10.1016/j.techfore.2020.120040

28. Lee, W.J., Lee, W.K. and Sohn, S.Y., (2016), "Patent network analysis and quadratic assignment procedures to identify the convergence of robot technologies", PloS one, Vol. 11, No. 10, e0165091. https://doi.org/10.1371/journal.pone.0165091

29. Li, Q., Maggitti, P.G., Smith, K.G., Tesluk, P.E. and Katila, R. (2013), “Top management attention to innovation: The role of search selection and intensity in new product introductions", Academy of Management Journal, Vol. 56, No. 3, pp.893-916. https://doi.org/10.5465/amj.2010.0844

30. Mäki, U. (2013) "Performativity: Saving Austin from MacKenzie", in: Karakostas V., Dieks D. (Eds) EPSA11 Perspectives and Foundational Problems in

International Journal of Management and Applied Research, 2021, Vol. 8, No. 3 
Philosophy of Science. The European Philosophy of Science Association Proceedings, Vol. 2. Cham: Springer. pp. 443-453. https://doi.org/10.1007/978-3319-01306-0_36

31. Marti, E. and Gond, J.P. (2018), "When do theories become self-fulfilling? Exploring the boundary conditions of performativity", Academy of Management Review, Vol. 43, No. 3, pp.487-508. https://doi.org/10.5465/amr.2016.0071

32. Norman, D.A. (1999), "Affordance, conventions, and design", Interactions, Vol. 6, No. 3, pp.38-43. https://doi.org/10.1145/301153.301168

33. Orlikowski, W.J., (2005), "Material works: Exploring the situated entanglement of technological performativity and human agency", Scandinavian Journal of Information Systems, Vol. 17, No. 1, Article 6.

34. Orlikowski, W.J. (2007), "Sociomaterial practices: Exploring technology at work", Organization studies, Vol. 28, No. 9, pp.1435-1448. https://doi.org/10.1177\%2F0170840607081138

35. Peng, Y.-N. and Sanderson, S. W. (2014), "Crossing the Chasm with Beacon Products in the Portable Music Player Industry", Technovation, Vol. 34, No. 2, pp. 77-92.

36. Pickering, A. (1995). The Mangle of Practice: Time, Agency, and Science, Chicago: The University of Chicago Press.

37. Rip, A. (2018), "Processes of technological innovation in context-and their modulation", in: Futures of Science and Technology in Society. Wiesbaden: Springer VS, pp. 49-73. https://doi.org/10.1007/978-3-658-21754-9_4

38. Rogers, E.M. (1995), Diffusion of Innovations, New York: Free Press.

39. Saheb, T. and Saheb, T. (2020), "Understanding the development trends of big data technologies: an analysis of patents and the cited scholarly works", Journal of Big Data, Vol. 7, No. 1, pp.1-26. https://doi.org/10.1186/s40537-020-00287-9

40. Tidd, J., Bessant, J. and Pavitt, K. (2005), Managing innovation: integrating technological, market and organizational change. Hoboken: John Wiley \& Sons.

41. van Dijk, L. and Rietveld, E. (2017), "Foregrounding Sociomaterial Practice in Our Understanding of Affordances: The Skilled Intentionality Framework", Frontiers in Psychology, Vol. 7, 1969, https://doi.org/10.3389/fpsyg.2016.01969

42. Wise, S. (2014), "Can a team have too much cohesion? The dark side to network density", European Management Journal, Vol. 32, No. 5, pp.703-711. https://doi.org/10.1016/j.emj.2013.12.005

International Journal of Management and Applied Research, 2021, Vol. 8, No. 3 
Developing A Conceptual Model that Illuminates the Dynamics of Performativity within Technological Innovation

43. Zizlavsky, O. (2013), "Past, Present and Future of the Innovation Process", International Journal of Engineering Business Management, https://doi.org/10.5772/56920

International Journal of Management and Applied Research, 2021, Vol. 8, No. 3 